\title{
Composição e Propriedades Reológicas da Goma do Angico (Anadenanthera Macrocarpa Benth).
}

\author{
André G. da Silva, J udith F. Rodrigues e Regina Célia M. de Paula
}

Resumo: A goma do angico foi purificada através de três estágios, cada um deles envolvendo dissolução em água e precipitação em etanol. As duas primeiras precipitações foram efetuadas em presença de $\mathrm{NaCl}$ e a última, em ausência. Os teores de umidade, cinza, proteína e cátions foram determinados para a goma nos vários estágios de purificação. A composição do polissacarídeo, obtida por HPLC, foi: $67,8 \%$ de arabinose, $24,1 \%$ de galactose e $2,0 \%$ de ramnose. O teor de 5,9\% de ácido urônico foi calculado a partir de titulação condutométrica. Os cátions presentes na goma bruta $\left(\mathrm{Na}^{+}, \mathrm{K}^{+}, \mathrm{Ca}^{2+}, \mathrm{Mg}^{2+} \mathrm{e} \mathrm{Fe} \mathrm{Fe}^{3+}\right)$ foram analisados por absorção atômica e gradualmente substituídos por $\mathrm{Na}^{+}$. O teor de proteína, no entanto, não diminuiu significativamente ao longo das purificações, o que pode ser um indicativo de que ela se encontra agregada ao polissacarídeo. $\mathrm{O}$ estudo por GPC sugere a presença de um complexo polissacarídeo-proteina de massa molar $7,9 \times 10^{5} \mathrm{~g} /$ mol e de polissacarídeos de massa molar $8,3 \times 10^{4} \mathrm{~g} / \mathrm{mol} \mathrm{e} 2,2 \times 10^{4} \mathrm{~g} / \mathrm{mol}$. A goma do angico apresenta baixa viscosidade e Energia de ativação de fluxo $16,8 \mathrm{~kJ} / \mathrm{mol}, 17,2 \mathrm{~kJ} / \mathrm{mol}$ e $17,7 \mathrm{~kJ} / \mathrm{mol}$, respectivamente para soluções $2 \%, 3 \%$ e $5 \%$. Comparação com outros polissacarídeos indica que a macromolécula é ramificada, mas em menor grau do que a goma arábica e a goma do cajueiro.

Palavras-chave: Goma, polissacarídeo, angico, reologia.

\section{Introdução}

Gomas naturais são polissacarídeos obtidos de exsudatos de troncos de árvore, de sementes, de algas ou por fermentação microbiológica, que sofrem hidratação em água fria ou quente, formando dispersões coloidais, soluções altamente viscosas ou, até mesmo, géis. Elas têm inúmeras aplicações tecnológicas, tais como: agentes espessantes, gelificantes, emulsificantes, floculantes, clarificantes, encapsuladores, controladores de caloria, além de adesivos, inibidores de cristalização, protetores coloidais, formadores de filme, estabilizadores de espuma e de suspensão $0^{[1]}$.
As gomas têm sido utilizadas, também, como substrato para cromatografia de afinidade no isolamento e purificação de proteínas. Neste caso elas são empregadas após reticulação com epicloridrina ${ }^{[2,3]}$. Os íons metálicos presentes nas gomas podem interagir de forma diferenciada com as proteínas ${ }^{[4]}$, devendo alterar o padrão de eluição. O controle destes cátions torna-se de especial importância em gomas a serem utilizadas para este fim.

A goma do angico é exsudada do tronco de certas espécies botânicas da família das leguminosas mimosáceas (gênero Piptadênia). Esta árvore é encontrada nativa e em abundância por todo o territó- 
rio nacional e pode pertencer a várias espécies, dentre as quais: angico branco, angico do campo, angico roxo, angico verdadeiro ${ }^{[5]}$. No Estado do Ceará a espécie mais comum é a do angico do campo, anteriormente denominada como Piptadênia Macrocarpa Benth. Desde 1971 passou a ser conhecida como Anadenanthera Macrocarpa Benth ${ }^{[6]}$.

Rangel (1943) ${ }^{[7]}$ determinou os teores de umidade e cinza e a presença de arabinose e galactose na goma do angico do Ceará. Rosenthal (1955) ${ }^{[8]}$ detectou a presença de arabinose e galactose, além de xilose e ribose.

O objetivo do presente trabalho é a purificação e caracterização da goma do angico do Ceará (Anadenanthera Macrocarpa Benth) no que diz respeito aos teores de cinzas, umidade, proteína, ácidos urônicos, açúcares neutros e cátions, assim como a distribuição de massa molar. Muitas das aplicações industriais das gomas estão relacionadas com as suas propriedades reológicas. $\mathrm{O}$ efeito da temperatura e da concentração sobre a viscosidade de soluções da goma do angico será discutido.

\section{Parte Experimental}

\section{Processos de isolamento e purificação}

A goma bruta foi coletada em abril de 1989 de exsudatos naturais de angicos nativos oriundos da Fazenda Charita, localizada no município de Parambu, na região Centro-Oeste do Estado do Ceará. O sequenciamento dos estágios de purificação foi o seguinte: ISOLAMENTO, $1^{\text {a }}$ PURIFICAÇÃO, $2^{\text {a }}$ PURIFICAÇÃO.

Nos processos de isolamento e purificação foram adotados os métodos descritos por Rodrigues et al. ${ }^{[9]}$ e Costa et al. ${ }^{[10]}$ com pequenas modificações. O Fluxograma 1 apresenta as etapas comuns aos vários processos. No isolamento a dissolução foi feita através de agitação magnética por 24 horas, com ajustes periódicos de $\mathrm{pH}$ (entre 6,0 e 7,0) e em presença de $\mathrm{H}_{2} \mathrm{O}_{2}$, para descolorir a solução. Para facilitar a precipitação, foi necessária a adição de $\mathrm{NaCl}(0,5 \mathrm{~g} /$ $100 \mathrm{~mL}$ de solução de goma). Na primeira purificação, ainda foi necessária a adição de $\mathrm{H}_{2} \mathrm{O}_{2}$, embora em menor quantidade; a precipitação foi efetuada em excesso de $\mathrm{NaCl}$. A segunda purificação foi efetuada segundo o fluxograma básico.

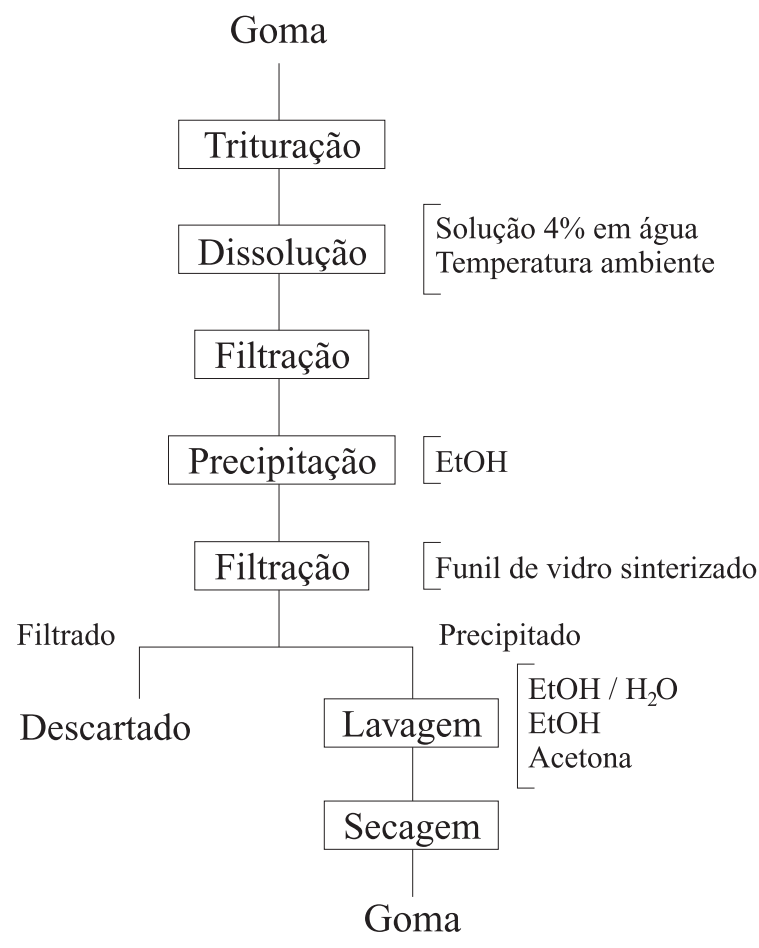

Fluxograma 1. Fluxograma básico contendo as etapas comuns aos vários estágios de purificação da goma do angico.

\section{Caracterização}

As amostras de goma bruta, isolada, purificada I e purificada II foram analisadas no que se refere a seus teores de umidade, cinza e nitrogênio (proteína). Foram determinados ainda os teores de cátions, de monossacarídeos neutros após hidrólise e de grupamentos carboxílico.

O teor de umidade foi obtido por diferença de peso após aquecimento à $105^{\circ} \mathrm{C}$ e o teor de cinza por aquecimento em mufla à $600^{\circ} \mathrm{C}$ e à $900^{\circ} \mathrm{C}$, todos efetuados até peso constante. $\mathrm{O}$ teor de proteína foi calculado a partir do resultado da análise elementar de $\mathrm{N}$, fazendo-se uso da relação \% $\mathrm{N}$ x 6,25 (Marks et al.) ${ }^{[11]}$.

Para a determinação de $\mathrm{Na}^{+}$e $\mathrm{K}^{+}$foi utilizado um fotômetro de chama B 262 da Micronal e para análise de $\mathrm{Ca}^{2+}, \mathrm{Mg}^{2+}$ e $\mathrm{Fe}^{3+}$, um espectrofotômetro de absorção atômica 3030B da Perkin-Elmer.

A composição dos monossacarídeos neutros foi calculada através de HPLC. Uma amostra de 200 $\mathrm{mg}$ de goma foi hidrolisada com $4 \mathrm{~mL}$ de ácido trifluoroacético durante 2 horas à $100^{\circ} \mathrm{C}$. Para eliminar o excesso de ácido, foi adicionado $\mathrm{MeOH}$ e a solução, concentrada após cada adição do álcool. Foram empregadas uma coluna catiônica $\left(\mathrm{Pb}^{2+}\right)$ e uma $\mathrm{NH}_{2}$ (Spherisorb). Na catiônica, utilizou-se água como solvente à temperatura de $80^{\circ} \mathrm{C}$, e na $\mathrm{NH}_{2}$, acetonitrila- 
água (85:15) como solvente e temperatura ambiente. Um detetor de índice de refração foi utilizado para analisar o hidrolisado.

A porcentagem de grupamentos carboxílico (ácidos urônicos), na forma neutralizada (sal de $\mathrm{Na}$ ) e na forma ácida, foi obtida por titulações condutométricas com $\mathrm{HCl} 0,01 \mathrm{M}$ e $\mathrm{NaOH} 0,01 \mathrm{M}$, respectivamente, como utilizado por Casu e Gennaro ${ }^{[12]}$ e por Pal e Bhattacharyya $^{[13]}$. Empregou-se um condutivímetro B331 da Micronal, com eletrodo de platina platinizado, de constante $0,63 \mathrm{~cm}^{-1}$, à temperatura de $29,0 \pm 0,1^{\circ} \mathrm{C}$.

Todas as análises foram feitas, no mínimo, em duplicata.

As massas molares médias foram estimadas através de um cromatógrafo líquído HPLC da Pharmacia, acoplado com um detector UV-1 ( $\lambda$ em $280 \mathrm{~nm})$ e interligado com um medidor de densidade (PAARDMA-60/602). Uma série de colunas Ultrahydrogel foi utilizada. Para minimizar o efeito da carga iônica dos polieletrólitos, todos experimentos foram realizados em $\mathrm{NaCl} 1 \mathrm{M}$. Amostras de dextrana de massa molar entre $6,0 \times 10^{4} \mathrm{~g} / \mathrm{mol}$ e $5,0 \times 10^{5} \mathrm{~g} / \mathrm{mol}$ e de goma arábica de massa molar $3,5 \times 10^{5} \mathrm{~g} / \mathrm{mol}$ foram usadas como padrão.

As medidas de viscosidade foram efetuadas em soluções diluídas preparadas por agitação magnética durante 12 horas, seguida de filtração. Para a determinação da viscosidade intrínseca foi utilizado um viscosímetro de Ubbelohde com diâmetro de capilar de $0,3 \mathrm{~mm}$. Solução de $\mathrm{NaCl} 1 \mathrm{M}$, com tempo de escoamento de $290 \mathrm{~s}$, à $25,0 \pm 0,1^{\circ} \mathrm{C}$, foi empregada como solvente. Para estudar o efeito da temperatura, foram utilizadas soluções da goma purificada II nas concentrações de $2 \%, 3 \%$ e $5 \%$ e viscosímetro de Ostwald com diâmetro de capilar $0,8 \mathrm{~mm}$. As soluções foram progressivamente aquecidas a partir de $10^{\circ} \mathrm{C}$ até $70^{\circ} \mathrm{C}$, a uma velocidade de aquecimento de $1{ }^{\circ} \mathrm{C} /$ min. Medidas durante o resfriamento $\left(70^{\circ} \mathrm{C}\right.$ para $10^{\circ} \mathrm{C}$ ) foram, também, efetuadas. Todos os tempos de escoamento representam a média de, pelo menos, três determinações.

\section{Resultados e Discussão}

\section{Composição}

A Tabela 1 apresenta alguns dados característicos das gomas bruta, isolada e purificadas. O teor de umi-
Tabela 1. Característica da goma do angico em vários estágios de purificação

\begin{tabular}{|c|c|c|c|c|}
\hline \multirow{2}{*}{ Característica } & \multicolumn{4}{|l|}{ Goma } \\
\hline & bruta & isolada & purificada I & purificada II \\
\hline Rendimento (\%) & - & 68 & 78 & 72 \\
\hline Umidade (\%) & 10,5 & 11,0 & 9,0 & 7,3 \\
\hline $\begin{array}{r}\text { Cinza }(\%) \text { a } 600^{\circ} \mathrm{C} \\
\text { a } 900^{\circ} \mathrm{C}\end{array}$ & $\begin{array}{l}1,6 \\
1,0\end{array}$ & $\begin{array}{l}2,5 \\
1,5\end{array}$ & $\begin{array}{l}6,4 \\
1,5\end{array}$ & $\begin{array}{l}1,8 \\
1,6\end{array}$ \\
\hline$\% \mathrm{~N}$ & 2,1 & 1,0 & 0,9 & 0,9 \\
\hline Proteina $(\%)$ & - & 6,4 & 5,7 & 5,8 \\
\hline $\begin{array}{l}\text { Ácidos urônicos (\%) } \\
\text { Forma salina } \\
\text { Forma ácida }\end{array}$ & - & $\begin{array}{l}5,9 \\
0,0\end{array}$ & $\begin{array}{l}5,9 \\
0,0\end{array}$ & $\begin{array}{l}5,9 \\
0,0\end{array}$ \\
\hline $\begin{array}{l}\text { Monossacarídeos neutros } \\
(\%) \\
\text { arabinose } \\
\text { galactose } \\
\text { ramnose }\end{array}$ & - & - & - & $\begin{array}{c}67,8 \\
24,1 \\
2,0\end{array}$ \\
\hline
\end{tabular}

dade foi utilizado para correção de massa. Os teores de cinza à $600^{\circ} \mathrm{C}$, registrados para as gomas isolada e purificada I, estão acima dos demais. O processo de evaporação do $\mathrm{NaCl}$ começa à $700^{\circ} \mathrm{C}$ e termina à $850^{\circ} \mathrm{C}$ (Plitay) ${ }^{[14]}$. A diminuição do percentual de cinza obtido à $900^{\circ} \mathrm{C}$ confirma a presença de $\mathrm{NaCl}$, certamente coprecipitado durante o processo de obtenção das referidas gomas. Comportamento semelhante foi observado para a goma do cajueiro obtida por processo de purificação similar ${ }^{[14]}$.

O maior teor de nitrogênio registrado para a goma bruta pode ser explicado não só pela maior quantidade de proteína, como também, pela presença de outros compostos nitrogenados, tais como aminoácidos. Portanto, não parece adequado, neste caso, calcular a porcentagem de proteína através da sistemática usual ( \% N x 6,25).

As porcentagens de proteína registradas na literatura para arabino-galactanas variam de $0,4 \%$ (Pin-

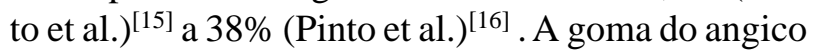
purificada apresenta um teor de proteína $(5,8 \%)$ dentro desta faixa. A permanência deste residual, mesmo após as seguidas purificações, pode ser um indicativo de que a proteína se encontra agregada ao polissacarídeo.

Analíses através de HPLC, usando as colunas amino e catiônica, confirmam a presença dos seguintes açúcares neutros: $67,8 \%$ de arabinose, $24,1 \%$ de galactose e $2,0 \%$ de ramnose. A coluna amino foi utilizada, também, para possibilitar a dedução da inexistência de glicose. Xilose e ribose, também, não foram detectadas, como sugerido por Rosenthal ${ }^{[5]}$. O teor de ácidos urônicos é de 5,9\%, o qual permanece constante ao longo dos estágios de purificação. To- 


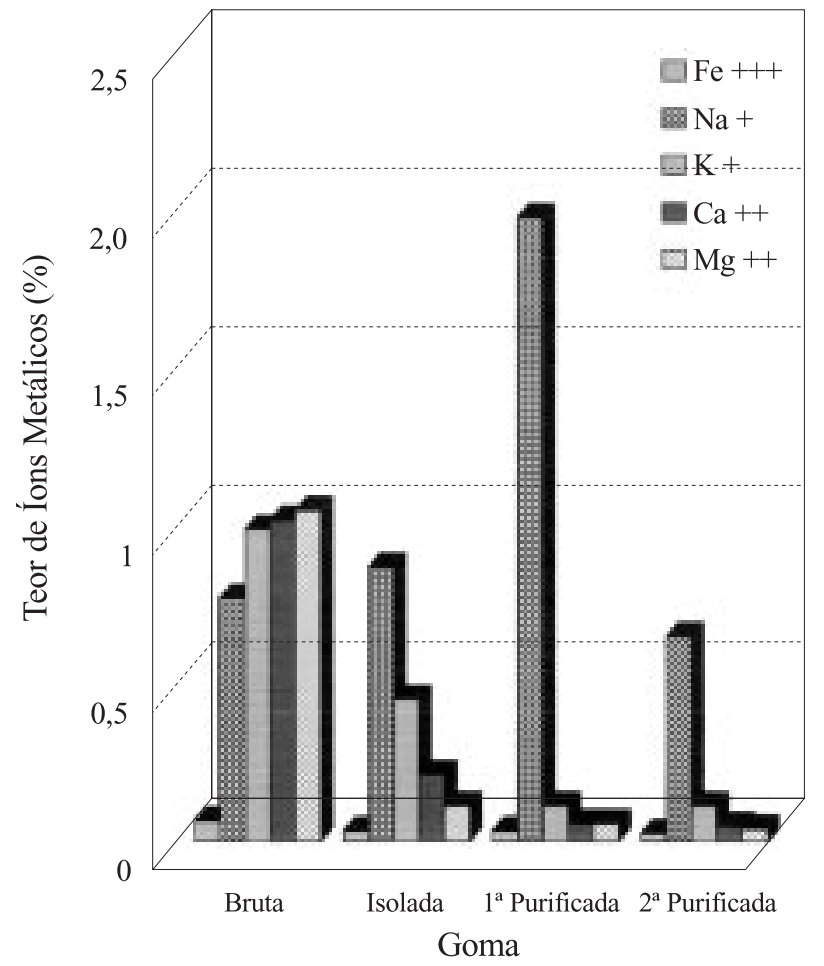

Figura 1. Distribuição dos teores de $\mathrm{Na}^{+}, \mathrm{K}^{+}, \mathrm{Ca}^{2+}, \mathrm{Mg}^{2+}$ e $\mathrm{Fe}^{3+}$ nas amostras de goma de angico obtidas nos vários estágios de purificação.

dos os grupamentos $\mathrm{RCOOH}$ presentes inicialmente no heteropolissacarídeo foram neutralizados, tendose as amostras de goma totalmente na forma de sal. Paula et al. ${ }^{[16]}$ identificaram o ácido glucurônico como o açúcar ácido presente na goma do angico.

Através da Figura 1 verifica-se que os cátions presentes na goma bruta são, principalmente, $\mathrm{Na}^{+}$, $\mathrm{K}^{+}, \mathrm{Ca}^{2+} \mathrm{e} \mathrm{Mg}^{2+}$. Constata-se, também, uma diminuição nos teores de $\mathrm{K}^{+}, \mathrm{Ca}^{2+}$ e $\mathrm{Mg}^{2+}$ ao longo das purificações, cátions estes que estariam sendo substituídos por $\mathrm{Na}^{+}$. A goma purificada I, no entanto, apresenta um percentual de $\mathrm{Na}^{+}$anormalmente elevado, mas que é condizente com a coprecipitação de $\mathrm{NaCl}$. $\mathrm{Na}$ goma purificada II, o teor de $\mathrm{Na}^{+}$decresce, confirmando assim a retirada do seu excesso.

O teor de cálcio é comparável ao reportado para gomas de Albizia lebbeck ${ }^{[17]}$ e de Phithecellobium ${ }^{[18]}$. Os teores de sódio e, principalmente, os de potássio e magnésio são, no entanto, relativamente superiores.

Observa-se que, mesmo após a $2^{\mathrm{a}}$ purificação, aproximadamente $20 \%$ dos cátions não foram substituídos por $\mathrm{Na}^{+}$, o que indica que eles estão fortemente ligados à goma. Na goma do cajueiro, cujo teor de proteína é aproximadamente seis vezes menor, no final da segunda purificação apenas 5\% dos íons presentes não são substituídos por $\mathrm{Na}^{+}(\mathrm{Costa} \text { et al. })^{[10]}$. A retenção dos cátions metálicos parece estar associada à retenção de proteína.

\section{Cromatografia de Permeação em Gel (GPC)}

Os cromatogramas de GPC para a goma do angico purificada estão mostrados na Figura 2. Dois picos principais (A e B) foram claramente detectados através de densidade (cromatograma I). Um pico muito intenso, correspondente ao A, e um de intensidade bem menor, denominado de $\mathrm{C}$, foram detectados por absorção na região do ultravioleta - em $280 \mathrm{~nm}$ (cromatograma II). Os grupos cromóforos da goma absorvem somente no ultravioleta distante, sendo as transições eletrônicas para $\mathrm{CO}_{2} \mathrm{He} \mathrm{CO}_{2}^{-}$localizadas em 200-210 nm e para hidroxilas, abaixo de 180 $\mathrm{nm}^{[20]}$. Por outro lado, proteínas absorvem bem em $280 \mathrm{~nm}$, devido aos seus aminoácidos aromáticos ${ }^{[21]}$.

Levando-se em conta as indicações anteriores (retenção de proteína e de íons metálicos) e as obtidas

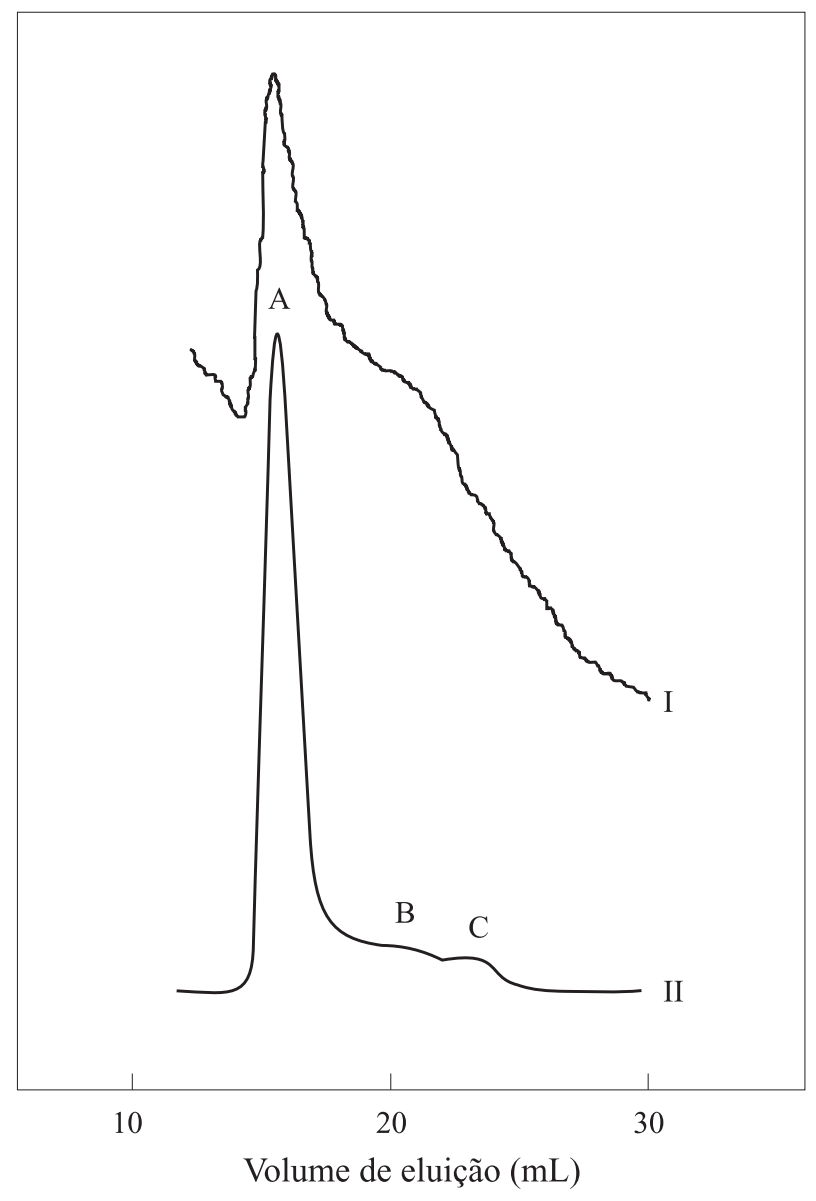

Figura 2. Cromatogramas GPC da goma angico purificada usando-se: (I) detetor de densidade, (II) detetor de absorção na região do U.V. Solvente $\mathrm{NaCl} 1 \mathrm{M}$. 
por GPC pode-se inferir que o pico A corresponde a um complexo polissacarídeo-proteína. Paula e Rodrigues $^{[22]}$ concluíram, por experimentos semelhantes, que a goma do cajueiro continha um complexo do mesmo tipo. Complexo arabino-galactano-proteína (AGP) foi detectado, também, na goma arábica ${ }^{[23-25]}$.

A goma do angico contem um complexo polissacarídeo-proteína de $\mathrm{M}_{\mathrm{pk}}$ em torno de 7,9 x $10^{5} \mathrm{~g} / \mathrm{mol}$, e polissacarídeos de massas molares, respectivamente, $8,3 \times 10^{4} \mathrm{~g} / \mathrm{mol} \mathrm{e} 2,2 \times 10^{4} \mathrm{~g} / \mathrm{mol}$, correspondentes aos picos B e C. Nestes políssacarídeos também estão presentes proteínas, mas em conteúdo significativamente inferior.

Comparando-se estes cromatogramas com aqueles obtidos em iguais condições (coluna, temperatura, solvente, equipamento e padrões), verifica-se que a massa molar média e a fração correspondente ao complexo protéico da goma do angico são superiores àquelas relativas à goma do cajueiro ${ }^{[10]}$. Na goma do angico o complexo protéico é a fração predominante, enquanto que na goma do cajueiro ela é minoritária (apenas 3,0\%).

$\mathrm{O}$ elevado teor de proteína e a permanência de íons metálicos como $\mathrm{Mg}^{2+}, \mathrm{Ca}^{2+}$ e $\mathrm{Fe}^{3+}$ podem acarretar dificuldades na utilização da goma do angico para o isolamento e purificação de proteínas. Outras utilizações podem ser testadas, dentre àquelas já consagradas à goma arábica, por exemplo.

\section{Propriedades Reológicas}

A goma do angico pode ser classificada na categoria das gomas pouco viscosas. A $25^{\circ} \mathrm{C}$, a solução $1 \%$ apresenta viscosidade $1,1 \mathrm{mPa} \mathrm{s}$, comparável à da goma do cajueiro $(1,0 \mathrm{mPa} \mathrm{s})^{[22]}$, e à da goma arábica $(1,8 \mathrm{mPa} \mathrm{s})^{[26]}$. Outras gomas industriais, como metil celulose, carboximetilcelulose, caraia, tragacanta, na mesma concentração, têm viscosidade bem superior, na faixa de 1.100 a $3.400 \mathrm{mPa} \mathrm{s}{ }^{[26]}$. A concentração tem influência moderada sobre a viscosidade da goma do angico, A solução $2 \%$ tem viscosidade de $1,4 \mathrm{mPa}$ s, enquanto as soluções $3 \% \mathrm{e}$ $4 \%$ têm viscosidade de $1,6 \mathrm{mPa}$ s e $2,7 \mathrm{mPa}$, respectivamente.

A viscosidade intrínseca da goma do angico variou pouco ao longo dos estágios de purificação: 10,9 $\mathrm{mL} / \mathrm{g}$ para a goma isolada, $10,2 \mathrm{~mL} / \mathrm{g}$ para a goma purificada I, e $10,8 \mathrm{~mL} / \mathrm{g}$ para a goma purificada II. Estes dados são indicativos da não ocorrência de fracionamento ao longo do isolamento e purificação. O maior valor de [ $\eta]$ para a goma do angico, quando comparado à goma do cajueiro $(8,8 \mathrm{~mL} / \mathrm{g})^{[22]}$ - outra arabinogalactana, pode ser indicativo de uma estrutura com menor grau de ramificação, ou um reflexo da maior porcentagem do complexo arabinogalactano-proteina. A influência do menor percentual de ácido urônico (5,9\% para a goma do angico e 6,3\% para a goma do cajueiro) certamente seria no sentido de diminuir a viscosidade intrínseca.

Apesar das soluções utilizadas terem sido bastante diluídas é importante estimar-se o valor da concentração crítica, $\mathrm{C}_{\mathrm{c}}{ }^{\#}$, que estabelece o limite do regime diluído. $\mathrm{O}$ valor médio de $\mathrm{C}_{\mathrm{c}}{ }^{\#}[\eta]$ proposto por Morris et al. ${ }^{[27]}$ é 4, para polissacarídeos com conformação aleatória, o que forneceria uma $\mathrm{C}_{\mathrm{c}}$ \# para a goma do angico de $37 \%$. Mesmo considerando o menor valor $\mathrm{de}_{\mathrm{c}} \mathrm{H}^{\#}[\eta]$, que é 1, para polissacarídeos de conformação rígida ${ }^{[28,29]}$, a concentração crítica seria $9 \%$. Desta forma, a goma do angico deve se comportar em regime diluído até concentração 37\%, ou, pelo menos, até 9\%. Todas as medidas foram feitas, então, em regime muito diluído (concentração abaixo de 5\%).

A viscosidade de soluções da goma do angico $(2 \%, 3 \%$ e $5 \%)$ decresce com o aumento da temperatura (Figura 3). Isto pode ser atribuído a: (a) requeri-

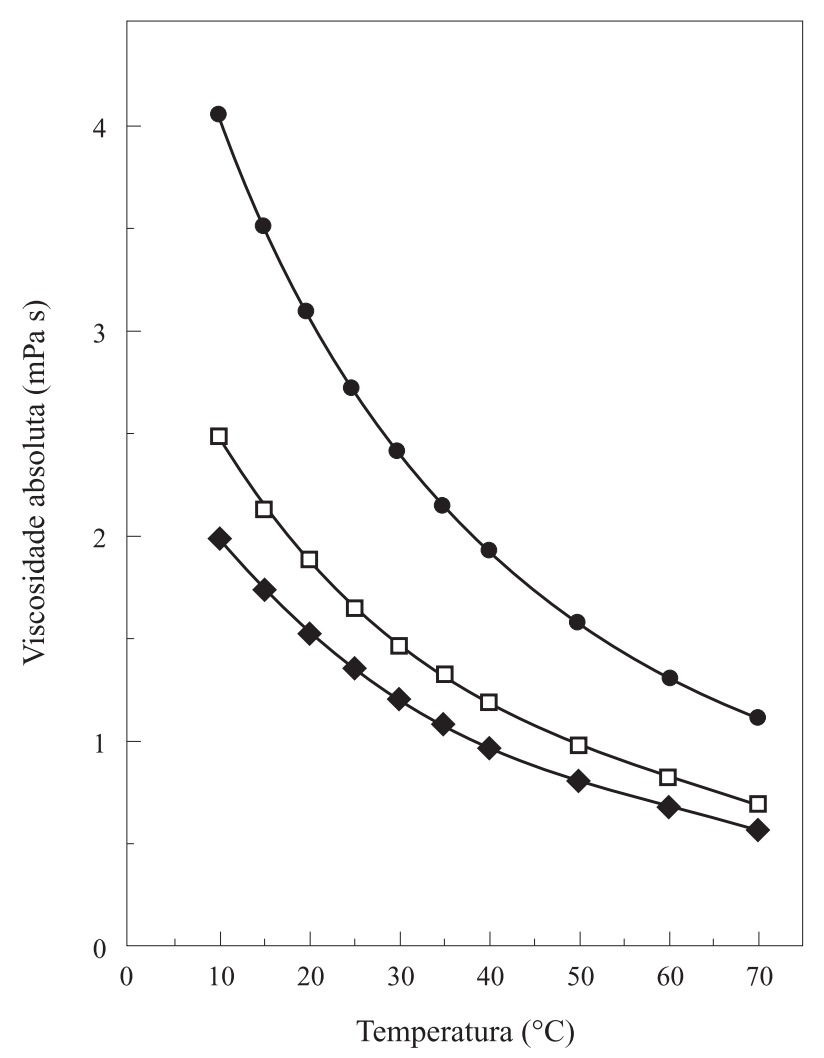

Figura 3. Efeito da temperatura sobre a viscosidade absoluta da goma de angico: $(\bullet)$ solução $2 \%$; $(\square)$ solução $3 \%$ e (•) solução 5\%. 
Tabela 2. Energias de ativação de fluxo para soluções aquosas de alguns polissacarídeos

\begin{tabular}{lcccc}
\hline \multirow{2}{*}{\multicolumn{1}{c}{ Polissacarídeo }} & \multicolumn{4}{c}{$\begin{array}{c}\text { Energia de ativação de fluxo } \\
\text { (kJ/mol) }\end{array}$} \\
\cline { 2 - 5 } & $\mathbf{2 \%}$ & $\mathbf{3 \%}$ & $\mathbf{4 \%}$ & $\mathbf{5 \%}$ \\
\hline Goma do cajueiro $^{[22]}$ & 15,6 & 16,2 & - & - \\
Goma arábica $^{[31]}$ & 15 & - & - & - \\
Alginato $^{[32]}$ & - & - & 23 & - \\
CMC-Na $^{[32]}$ & - & - & 27 & - \\
Goma do angico $^{*}$ & 16,8 & 17,2 & - & 17,7 \\
\hline
\end{tabular}

* presente trabalho

mento de energia para ultrapassar a barreira de energia potencial (Energia de ativação de fluxo) que existe quando ocorre a transição de uma posição de equilíbrio para outra; (b) degradação do polímero; ou (c) transição conformacional (ordenada - desordenada).

Nenhuma degradação foi constatada, uma vez que a curva de viscosidade versus temperatura de aquecimento foi a mesma para o resfriamento. A goma do angico, por sua semelhança com a goma do cajueiro e com a goma arábica, deve ser um heteropolissacarídeo ramificado, ou seja sem nenhuma conformação ordenada. A inexistência de variação brusca nas curvas da Figura 3 é uma confirmação da não ocorrência de transição entre conformação ordenada e desordenada. O efeito da temperatura deve estar associado, então, à Energia de ativação de fluxo (E).

A equação de Arrhenius-Frenkel-Eyring [30] $(\eta=B \exp (E / R T)$ expressa a dependência entre a viscosidade, a Energia de ativação de fluxo e a temperatura em Kelvin. As curvas de $\ln \eta$ vs $\mathrm{T}^{-1}$, obtidas a partir dos dados da Figura 3, apresentaram, para todas as concentrações estudadas, uma correlação linear simples. Isto confirma a inexistência de transição ordenada-desordenada. Os valores de E, determinados pelos coeficientes angulares das retas, foram: $16,8 \mathrm{~kJ} / \mathrm{mol}, 17,2 \mathrm{~kJ} / \mathrm{mol}$ e $17,7 \mathrm{~kJ} / \mathrm{mol}$, respectivamente para as soluções $2 \%, 3 \%$ e $5 \%$.

A Tabela 2 mostra uma comparação entre Energias de ativação de fluxo para algumas soluções de polissacarídeos. Esta Energia depende da flexibilidade e da interação entre as moléculas. No caso de soluções depende, também, da concentração. Para polímeros com massa molar maior do que $10^{4} \mathrm{~g} / \mathrm{mol}$, E é independente deste parâmetro ${ }^{[30]}$. Observa-se que os polímeros lineares e com fortes ligações inter e intramoleculares, como o alginato e a carboximetilcelulose, exibem os maiores valores de E. Os polissacarídeos ramificados, no caso as gomas de exsudato, apresentam menores valores de E. A goma do angico deve ter menor grau de ramificação do que a goma do cajueiro e a goma arábica e, também, uma maior possibilidade de interação entre as suas cadeias. Estas deduções são consistentes com as explicações fornecidas para as variações na viscosidade intrínseca.

\section{Conclusões}

A goma do angico, purificada através de 3 estágios, é um polissacarídeo composto de $67,8 \%$ de arabinose, $24,1 \%$ de galactose, $2,0 \%$ de ramnose e $5,9 \%$ de ácido glucurônico. Contém, ainda, 5,8 \% de proteína. O processo global de purificação não acarreta diminuição do teor de proteína, nem o fracionamento da macromolécula, mas possibilita a troca dos íons $\mathrm{K}^{+}, \mathrm{Ca}^{2+}, \mathrm{Mg}^{2+}$ e $\mathrm{Fe}^{3+}$ por $\mathrm{Na}^{+}$. Uma distribuição trimodal de massa molar foi observada, correspondente a um complexo polissacarídeo-proteína de massa molar em torno de 7,9 x $10^{5} \mathrm{~g} / \mathrm{mol}$, e a polissacarídeos de massas molares, respectivamente, $8,3 \times 10^{4} \mathrm{~g} / \mathrm{mol}$ e $2,2 \times 10^{4} \mathrm{~g} / \mathrm{mol}$.

Com relação as suas propriedades reológicas, a goma do angico, assim como a goma do cajueiro e a goma arábica, pode ser classificada na categoria das gomas pouco viscosas. A faixa da viscosidade de sua solução $1 \%$ é aproximadamente 1000 vezes menor do que a de gomas industriais, como metil celulose, carboximetilcelulose, caraia, tragacanta, na mesma concentração. Os valores da viscosidade intrínseca $(8,8 \mathrm{~mL} / \mathrm{g})$ e da Energia de ativação de fluxo $(16,8$ $\mathrm{kJ} / \mathrm{mol}, 17,2 \mathrm{~kJ} / \mathrm{mol}$ e $17,7 \mathrm{~kJ} / \mathrm{mol}$, respectivamente para as soluções de concentração $2 \%, 3 \%$ e $5 \%$ ) são um indicativo de que a estrutura do heteropolissacarídeo apresenta um menor grau de ramificação do que a da goma do cajueiro e a da goma arábica.

\section{Agradecimentos}

À Joaquim de Castro Feitosa, proprietário da Fazenda Charita, pela coleta da goma bruta, ao Prof. Fernando Galembeck pela obtenção dos cromatogramas de GPC e ao Prof. Barreto pela leitura crítica deste manuscrito. Ao CNPq e à CAPES pelas bolsas concedidas e à FUNCAP pelo apoio recebido. 


\section{Referências Bibliográficas}

1.Miller, J. N. - "Industrial Gums", in: Encyclopedia of Polymer Science and Engineering, John Wiley \& Sons, 7, p 589 (1987).

2. Appukuttan, P. S.; Surolia, A.; Bachhawat, B. K. Indian J. Biochem. Biophys. 14, 383 (1977).

3. Moreira, R. A.; Castelo-Branco, C. C.; Monteiro, A. C. O.; Tavares, R.O.; Beltramini, L.M. Phytochemistry , 47, 1183 (1998).

4. Wilkins, P. C.; Wilkins, R.G. - "Inorganic Chemistry in Biology", Oxford Science Publications, New York (1997).

5. Corrêa, M. P. - Dicionário das Plantas Úteis do Brasil e das Exóticas Cultivadas, Imprensa Nacional, Rio de Janeiro (1926).

6. Altschul, S. V. R. - "The Genus Anadenanthera in Ameridian Cultures", Bot. Mus. Harvard University, Cambridge, p 96 (1972).

7. Rangel, J.L. - "Goma do Angico", Instituto Nacional de Tecnologia, Rio de Janeiro (1943).

8. Rosenthal, F. R. T. - Revista de Química Industrial, 24, 17 (1955).

9. Rodrigues, J. F.; Paula, R. C. M.; Costa, S. M. O. - Polímeros : Ciência e Tecnologia, $n^{\circ} 1,31$ (1993).

10. Costa, S. M. O.; Rodrigues, J.F.; Paula, R. C. M. - Polímeros : Ciência e Tecnologia, $n^{\circ}$ 2, 49 (1996).

11. Marks, D . L.; Baum, R. B.; Swain, T. - Analytical Biochem., 147, 136 (1985).

12. Casu, B.; Gennaro, U. - Carbohyd. Res., 39, 168 (1975).

13. Pal, M. K.; Bhattacharyya, A K. - Makromol. Chem., 185, 2241 (1984).

14. Plitay, G. ( ed.), - Atlas of Thermoanalytical Curves, Heyden e Son Ltda, Hungria, vol 1 (1973).

15. Pinto, G. L.; Nava, M.; Martínez, M.; Rivas, C. Biochem. Syst. Ecol., 21, 463 (1993).
16. Pinto, G. L.; Martínez, M.; Ortega, S.; Villavicencio, N.; Borjas, L. - Biochem. Syst. Ecol., 21, 795 (1993).

17. Paula, R.C.M.; Budd, P. M.; Rodrigues, J. F. Polym. International, 44, 55 (1997).

18. Martínez, M.; Pinto, G. L.; Alvárez, S.; Troconis, N. G.; Ocando, E.; Rivas, C. - Biochem. Syst. Ecol., 23, 843 (1995).

19. Pinto, G. L.; Martínez, M.; Gotera, O. G.; Vera, A.; Rivas, C.; Ocando, E., - Biochem. Syst. Ecol. 23, 849 (1995).

20. Davidson, E. A. - Carbohydrate Chemistry, Holt, Rineheart e Winston Inc., New York, p 101 (1967).

21. Van Holde, K. E. - Physical Biochemistry, Prentice-Hall, New Jersey,cap 8 (1971).

22. Paula, R. C. M.; Rodrigues, J. F. - Carbohydr. Polym., 26, 177 (1995).

23. Fincher, G. B.; Stone, B. A.; Clarke, A. E - Ann. Rev. Plant. Physiol., 34, 47 (1983).

24. Vandevelde, M.C.; Fenyo, J.C. - Carbohydr. Polym., 5 , 251 (1985).

25. Duvallet, S.; Fenyo, J. C.; Vandevelde, M.C. Polym. Bull., 21, 517 (1989).

26. Meer, G.; Meer, W. A.; Tinker, J. - Food Technol., nov, 22 (1975).

27. Morris, E. H.; Cutler, A. N.; Ross-Murphy, S. B.; Rees, D. A.; Price, J. - Carbohydr. Polym., 1, 5 (1981).

28. Milas, M.; Rinaudo, M.; Knipper; Schuppiser, J. L. - Macromolecules 23, 2506 (1990).

29. Campana, S.; Andrade, C.; Milas, M.; Rinaudo, M. - Int. J. Biol. Macromol.,12, 379 (1990).

30. Vinogradov, G.V.; Malkin, A. Ya. - Rheology of Polymers, Viscoelasticity and Flow of Polymers, Mir, Moscou, p. 105-121 (1980).

31. Varfolomeeva, E.P.; Grinberg, V. Ya; Toistogusov, V. B. - Polym. Bull., 2, 613 (1980).

32. Narayan, K. S.; Ramasubramanian, V. - Indian J. of Technol., 20, 333 (1982).

Recebido: $17 / 07 / 97$

Aprovado: 23/03/98 